\title{
Escultura de Venus trobada a la població del Puig (València)
}

FERRAN ARASA I GIL ${ }^{1} \bullet$, MIQUEL ROSSELLÓ MESQUIDA²

(1) Dpt. Prehistòria, Arqueologia i $\mathrm{H}^{\mathrm{a}}$ Antiga. Universitat de València. Ferran.Arasa@uv.es

(2) Arqueòleg col·legiat núm. 13.508.miquelrome@gmail.com

Entre els mesos de desembre del 2016 i gener del 2017 tingué lloc una actuació arqueològica al solar del carrer Pintor Peiró núm. 6 de la població del Puig (l'Horta Nord), situat al centre històric de la vila i prop del Monestir de Santa Maria (figs. 1 i 2), que dirigiren M. Rosselló i I. García Villanueva (2017) ${ }^{1}$. Aquesta zona es troba inclosa en el PEP del Monestir per formar part de l'entorn d'afecció del BIC, i és considerada pel PGOU com a Centre Històric i resta inclosa en l'Àrea de Vigilància Arqueològica. L'actuació consistí en l'excavació d'una rasa perimetral de $120 \mathrm{~cm}$ d'amplària i $100 \mathrm{~cm}$ de profunditat, excepte pel costat que donava al carrer, i cinc traves de $50 \mathrm{~cm}$ d'amplària excavades una mitjana de $25 \mathrm{~cm}$ de fondària. Per indicació de l'arqueòleg inspector territorial s'amplià la intervenció amb l'excavació de dos sondeigs, localitzats un al peu del mur mitger $\mathrm{N}$ i l'altre a la vora del mur mitger $\mathrm{O}$ que tancava la parcel-la en època medieval.

A causa de l'escassa profunditat a què arribà l'excavació, els nivells més antics que es trobaren foren d'època medieval (ss. XIII-XIV) i corresponien a la construcció d'una casa, que es bastí de nou en la segona meitat del s. XVIII. En la primera meitat del s. XX la propietat es dividí i se n'edificà una nova, la derrocada que corresponia al núm. 6. D'aquesta època són una sèrie de dipòsits d'anivellament que anul·len les estructures anteriors. Els més destacats són les UUEE $1040=1041$, un paquet de materials de reble formats per restes d'enderrocs i fragments ceràmics que poden datar-se entre el final del s. XIX i el principi del XX. En la UE 1041 aparegué el fragment d'escultura romana que ací presentem (figs. 3 i 4). Possiblement degué portar-se des d'algun lloc pròxim amb la resta de materials emprats com a rebliment. Amb el permís de l'arqueòleg inspector i dels Serveis Territorials de Cultura la peça fou dipositada temporalment (febrer-juny del 2017) al laboratori del Departament de Prehistòria, Arqueologia i Història Antiga de la UV per tal de facilitar-ne la neteja i estudi.

És de marbre blanc de gra gros i mesura $51 \mathrm{~cm}$ d'altura, $27 \mathrm{~cm}$ d'amplària i $21 \mathrm{~cm}$ de grossària. La part conservada correspon a poc menys de la meitat inferior d'una figura femenina amb les cames cobertes per un mantell i els peus trencats (fig. 5). Per la part superior la fractura ha deixat tres plànols situats per davall del pubis i les natges i sobre el mantell que està enrotllat en la part 

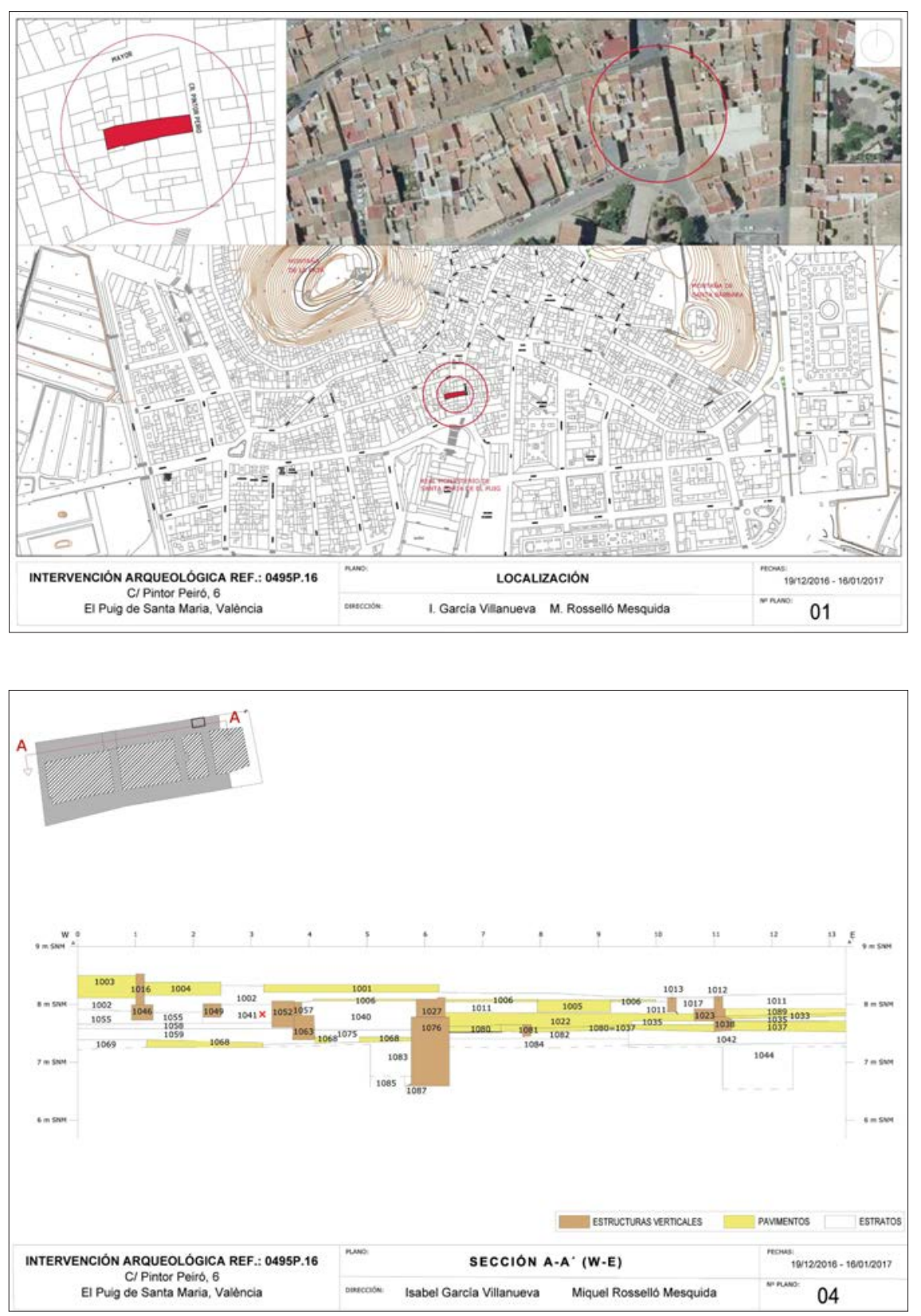

Fig. 1: Localització del solar del carrer Pintor Peyró, núm. 6 del Puig.
Fig. 2: Secció de l'excavació amb la localització de la UE 1041 on aparegué l'escultura. superior de les cuixes; aquestes resten visibles per la part posterior fins a una altura màxima de $3 \mathrm{~cm}$, de manera que des d'una perspectiva zenital en queda perfilada la secció amb una amplària de $25 \mathrm{~cm}$. Per davant es veu una petita escotadura de $2,5 \mathrm{~cm}$ d'altura que deu correspondre al segment que queda entre el pubis i el mantell. La separació entre les juntures de les cuixes, anterior i posterior, és de 7,5 cm. La unió d'aquestes amb el mantell està perfilada amb una ranura, més visible en l'esquerra. Per la part baixa la fractura es troba en la zona inferior de les cames, sobre els turmells. La peça presenta trencalls superficials en la part davantera, sobretot en la zona central de la cama dreta, i nombroses rascades i erosions, especialment en els plecs del mantell. En els solcs que formen 
Fig. 3: Planta de l'excavació amb la localització de la UE 1041 on aparegué l'escultura.

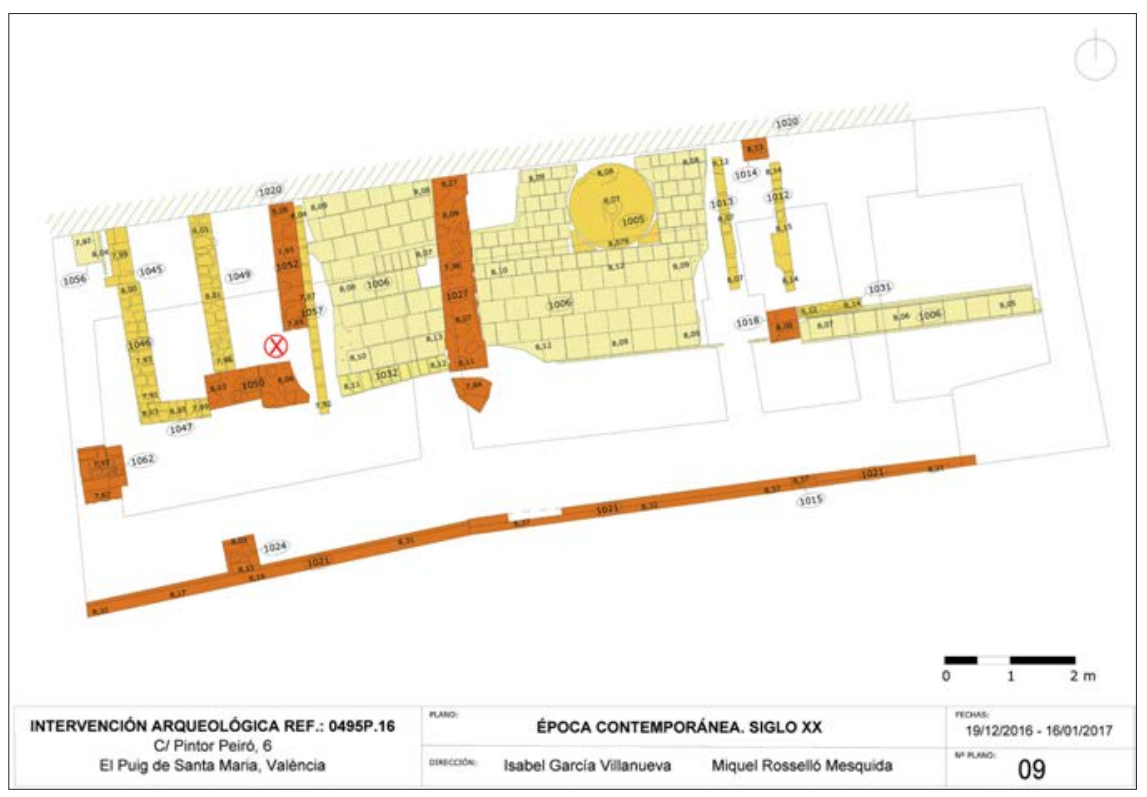

Fig. 4: L'escultura en el moment de la troballa a la UE 1041.

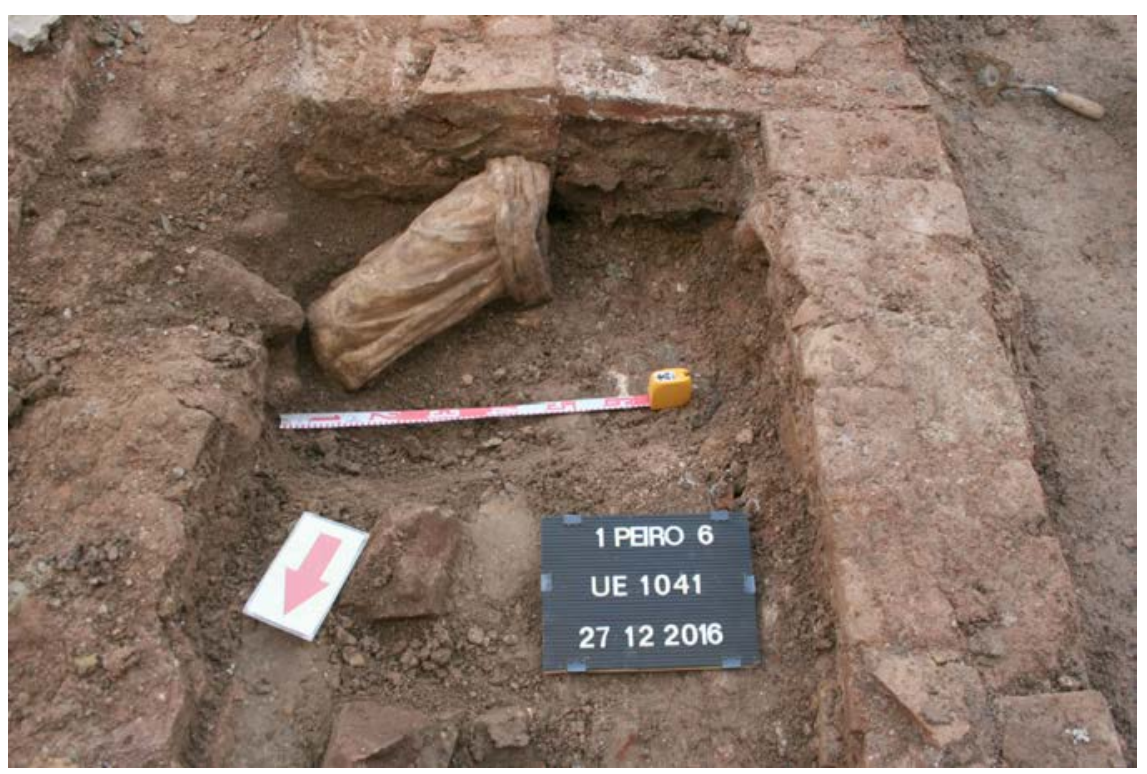

els plecs es veuen, especialment per darrere, algunes estries de poliment. Per les seues reduïdes dimensions degué ser només d'una peça.

La figura descansa sobre la cama esquerra i allibera la dreta, que està un poc doblada, de manera que devia estar lleugerament inclinada cap a aquell costat. L'engrossiment del mantell per davall de la cadera només es conserva per la part esquerra i per darrere, $i$ està inclinat de davant cap a darrere i d'esquerra a dreta. Per la part davantera, on devia situar-se per davall de la zona púbica, ha desaparegut completament. La part que se'n conserva està formada per tres plecs paral·lels, dels quals és més gruixut el central, que per darrere té una altura màxima de $7 \mathrm{~cm}$ i s'escindeix cap al costat esquerre. Per darrere la distància entre la seua vora i les cuixes és de 7,5 cm, de manera que se'n forma un plànol llis lleugerament inclinat cap a dins, amb dos plecs 


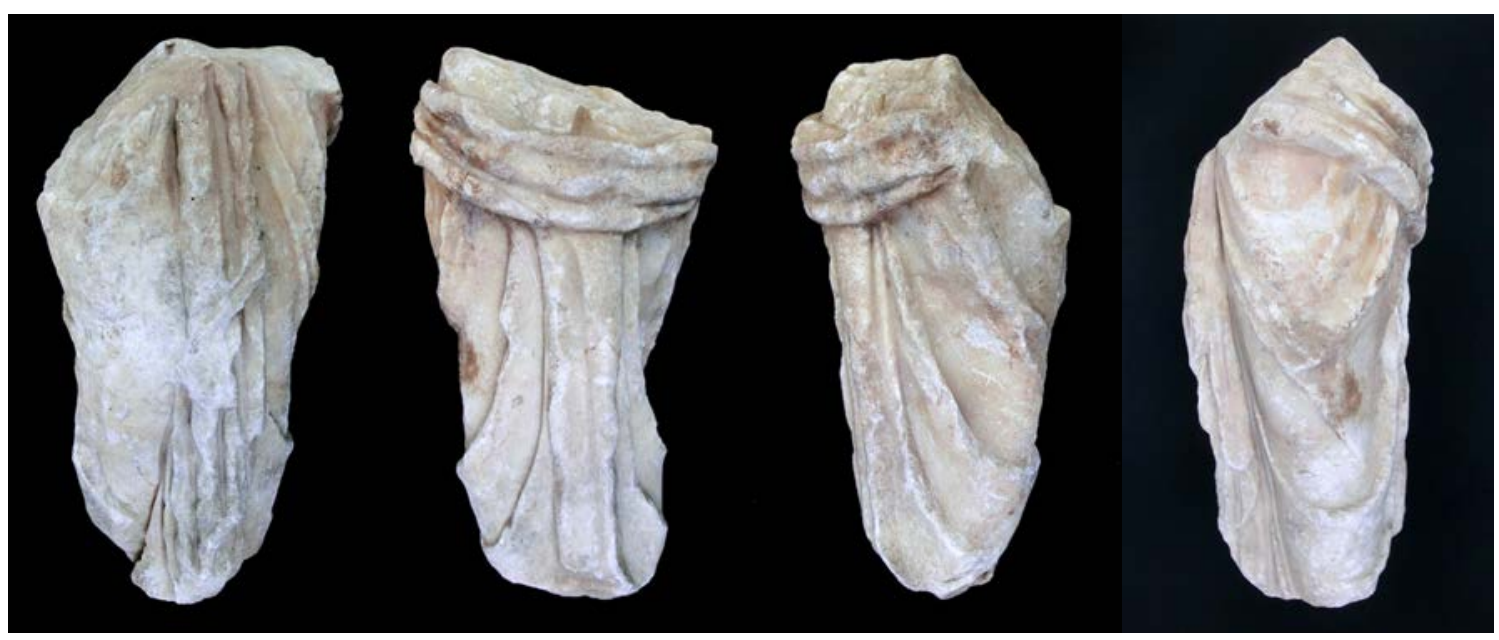

Fig. 5: Vistes anterior, posterior, dreta i esquerra de l'escultura de Venus.

poc marcats que les cenyeixen. Per davant, un extrem del mantell cau per la zona central formant plecs rectilinis separats per solcs profunds, més gruixuts en la part superior, on conserva l'inici que deu correspondre a la vora inferior de l'esmentat engrossiment. Cap a la meitat, la vora del mantell es creua en diagonal d'esquerra a dreta dibuixant una mena de essa que acaba en una zona erosionada, a partir d'on es divideix en diversos plecs més estrets que s'eixamplen un poc cap a l'extrem inferior, sobretot cap a la dreta, seguint la inclinació de la cama; ací, de nou la vora del mantell dibuixa una línia sinuosa cap a la dreta que acaba en el plànol de fractura.

La part conservada de la figura no permet determinar si es tractava del tipus més freqüent de Venus púdica que intenta tapar-se dirigint la mà esquerra cap al pubis, en alguns casos agafant el mantell directament amb aquella, mentre es cobreix els pits amb la dreta; o si es tracta del tipus Anadyomene mig vestida que representa la deessa eixint de la mar amb els braços alçats i eixugant-se els cabells amb les mans, mentre el mantell nugat se li escorre des dels malucs cap a les cuixes deixant al descobert de vegades el pubis i les natges. En ambdós casos la representació de la meitat inferior del cos és molt semblant: el mantell s'ha enrotllat a l'altura dels malucs, però en la part posterior ja deixa les natges parcialment descobertes; en el cas del tipus Anadyomene el mantell sol estar nugat al davant i en el de la Venus púdica se l'agafa directament amb la mà esquerra o en ocasions presenta un plec davanter creuat que cau entre les cames. El fet que no puguem saber la postura que adoptaven els braços, i que falte la part davantera de l'engrossiment del mantell, on podia trobar-se la mà o simplement un nus, impedeix precisar-ne el tipus ( $c f$. Landwehr 1993: 26-27, núm. 9, làm. 17b-c). Tampoc el drapejat ho facilita, ja que el tipus de Venus púdica presenta nombroses variants i entre elles n'hi ha alguna en què els plecs del mantell de la part posterior cauen verticalment, que també trobem en el tipus Anadyomene. En ambdós tipus la deessa va acompanyada de la figura del seu fill Eros o d'un dofí que en fan de suport.

Aquest tipus de vestidura apareix per primera vegada en el tipus Anadyomene mig vestida, una creació del període tardohel-lenístic que es data cap a la segona meitat del $\mathrm{s}$. III aE i compta amb nombroses rèpliques romanes (Delivorrias 1984, s. v. Aphrodite, LIMC, II: 76-77, núm. $667-$ 678). Un exemple de disposició vertical del plec central en la part posterior el podem veure en una figura conservada a Dresde que correspon també a la meitat inferior del cos i es data a principis del s. II (Knoll et al. 2011: 264-266, núm. 37). D'aquest tipus prengué la vestidura el conegut com a Afrodita Púdica parcialment vestida que tingué una gran difusió en l'època romana (Delivorrias 1984, s. v. Aphrodite, LIMC, II: 82-83, núm. 736-741). Entre les seues variants, el grup més nombrós és el d'aquelles en què la deessa descansa sobre la cama esquerra, com és el cas de l'estàtua del Puig, i el braç esquerre es dirigeix cap al pubis. Entre elles destaca la del Museu del Prado, del principi de l'època dels Severs, on la representació d'una petxina en època moderna impedeix saber si hi havia un nus a la part davantera (Schröder 2004: 167-171). 
Aquesta disposició del mantell per la part posterior la trobem en alguns casos d'estàtues incompletes d'ambdós tipus conegudes a la península. En podem veure dos exemples de la Bètica: un fragment de Venus púdica de La Encarnación (Sevilla) que data de mitjans del s. II dE (Oria 2013a: 414-416, fig. 5); i un altre fragment d'Italica que es data entre mitjan s. I dE i principis del II (Peña i Rodero 2004: 80-82, núm. 11, fig. 6).

Les representacions de Venus són freqüents en les villes itàliques (Neudecker 1988: 31), i a Pompeia trobem alguns exemplars de petit format que tenien una funció decorativa en jardins i viridaria (Carrella et al. 2008: 93, B 27; 134-135, C 23; 201,D 57). A Hispània se'n coneixen diversos exemples en ambients rurals de la Tarraconense $\mathrm{i}$ la Bètica (Koppel 1995: 37; Oria 2013: 241, n. 51). També decoren ambients termals (Manderscheid 1981: 32-33), com podem veure a Munigua, Lecrín (Granada) i Fuengirola (Màlaga) (Koppel 2004: 341-342, 349-350). Al País Valencià trobem un paral-lel aproximat en una figura desapareguda de Santa Pola (Alacant) (Arasa 2004: 333, fig. 16). Tanmateix, el millor exemplar d'Afrodita conservat en terres valencianes és l'anomenada Venus d'Ilici, una còpia del tipus Capitolí (Noguera 2002).

Desconeixem la procedència exacta d'aquesta escultura, però possiblement fou portada d'algun lloc pròxim, potser de la mateixa població. Al terme municipal del Puig hi ha diversos assentaments d'època altimperial, dels quals el més conegut és el del Vilar, una important vil·la que proporcionà un important conjunt escultòric (Arasa 2011). També als peus del Cabeçolet es coneix la troballa de restes romanes. A la població, en el mateix carrer Pintor Peiró, l'any 2004 es trobaren restes d'una necròpolis, i cap al S, al carrer Poeta Llorente l'any 1979 aparegueren restes d'un altre assentament (Badenes 2014: 71-72). Aquest conjunt de troballes assenyalen una important densitat de poblament en aquesta àrea del territori de Saguntum.

Per les seues proporcions pot deduir-se que degué ser una escultura de caràcter privat que possiblement decorava un ambient termal o de jardí d'alguna vil-la pròxima. A pesar del seu estat de conservació, creiem que és possible datar-la en el s. II pels volums compactes i poc modelats visibles especialment en els plecs de la cadera.

\section{NOTA}

1. Volem agrair la lectura prèvia del manuscrit a la professora Montserrat Claveria (UAB), així com les seues pertinents observacions.

\section{BIBLIOGRAFIA}

ARASA, F. (2004): Escultures romanes desaparegudes al País Valencià, $A P L \mathrm{XXV}, 301-344$.

ARASA, F. (2011): El Vilar (el Puig). La vil-la de P. Caecilius Rufus, Actes del III Congrés d'Estudis de l'Horta Nord, I (J. V. Frechina et al., eds.), València, 49-72.

BADENES, J. S. (2004): El castell de la Patà i el naixement del Puig de Santa Maria, El Puig.

CARRELlA, A.; D'ACUNTO, L. A.; INSERRA, N; SERPE, C. (2008): Marmora Pompeiana nel Museo Archeologico Nazionale di Napoli. Gli arredi scultorei delle case pompeiane, Roma.

GARCÍA VILLANUEVA, I.; ROSSELLÓ, M. (2017): Informe arqueológico preliminar. Calle Pintor Peiró $n^{\circ}$ 6, El Puig de Santa María, València. N/Ref.: 0495P.16, València.

KNOLL, K.; VORSTER, CH.; WOELK, M. (eds.) (2011): Skulpturensammlung Staaliche Kunstsammlungen Dresden. Katalog der antiken Bildwerke II. Idealskulptur der römischen Kaiserzeit 1, Munchen.

KOPPEL, E. M. (1995): La decoración escultórica de las villae romanas en Hispania, Poblamiento rural romano en el sureste de Hispania, Murcia, 27-48.

KOPPEL, E. M. (2004): La decoración escultórica de las termas en Hispania, Actas de la IV Reunión sobre escultura romana en Hispania (T. Nogales, L. J. Gonçalves, coord.), Madrid, 339-362.

LANDWER, Ch. (1993): Die römischen Skulpturen von Caesarea Mauretaniae I. Idealplastik, Berlin.

LIMC = Lexicon Iconographicum Mithologiae Classicae (1981 ss), Zürich-München.

MANDERSCHEID, H. (1981): Die Skulpturenausstattung des Kaiser zeitlichen Thermenanlagen, Berlin.

NEUDECKER, R. (1988): Die Skulpturenausstattung römischer Villen in Italien, Mainz am Rhein.

NOGUERA, J. M. (2002): La Venus de Ilici, Littera Scripta in honorem Prof. Lope Pascual, vol. 2, Murcia, 759-776.

ORIA, M. (2013): Hallazgos recientes de estatuaria doméstica hispalense: hermes, Venus y Eros sedente de La Encarnación, Sevilla, Actas de la VII Reunión de Escultura Romana en Hispania. Homenaje al Prof. Dr. Alberto Balil (F. Acuña, R. Casal, S. González Soutelo, eds.), Santiago de Compostela, 411-424.

PEÑA, A.; RODERO, S. (2004): Un conjunto de esculturas de pequeño formato procedente de Italica (Santiponce, Sevilla), Romula 3, 63-102.

SCHRÖDER, S. F. (2004): Catálogo de las esculturas antiguas del Museo del Prado, II: Plástica ideal, Madrid. 